\title{
Exploring the Development Path of Supply-side Structural Reform of Sports Industry Under the New Normal*
}

\author{
Hai Wang \\ Department of Physical Education \\ Guizhou University of Finance and Economics \\ Guizhou, China 550025
}

\begin{abstract}
-2017 is a year for deepening supply-side structural reforms. It is also the initial year of China's sports industry reform. It analyzes the new normal and supply-side structural reforms, the new normal of sports industry. And it believes that promoting the supply-side structural reform is the only way for the development of China's sports industry under the new normal. It is recommended to carry out the supplyside structural reform of the sports industry in accordance with the diversified sports demand of the people. And it strives to realize the new vision of "strong sports promoting China" proposed by General Secretary Xi Jinping, and the innovation, coordination, green, open, and shared development of sports industry.
\end{abstract}

Keywords-sports industry; new normal; supply side; reform and development

\section{INTRODUCTION}

With the influence of China's social and economic development, especially the "healthy China" strategy and the Olympic effect, the sports industry has entered a period of golden development, and it has become an important force to promote the rapid and healthy development of the social economy. This year is a crucial year for the supply-side structural reform. At the beginning of the New Year, General Secretary Xi Jinping pointed that during the 30th collective study of the Central Political Bureau, promoting the supplyside structural reform is an inevitable choice for China's economic development to enter a new normal. It is a strategic line that must be established in China's macroeconomic management under the new normal of economic development [1]. This year is also the initial year of China's sports industry reform, the Football Association decoupling and the Basketball Association re-election. The preparations for the 2022 Winter Olympics opened. The sports industry has entered the critical period of reform and development. However, in general, China's sports industry still has problems such as low development level, unreasonable structure, weak market vitality and creativity,

*Fund Project: Guizhou Provincial Philosophy and Social Science Planning Project (14GZQN30); Young Teachers Talent Program of Guizhou University of Finance and Economics in 2016. CLC number: G80-05 Document code: A insufficient supply of products, and insufficient incentives for mass sports consumption [2]. Reform is the driving force for development. Without reform, there will be no development. There are some core issues needing urgent research and resolution: to adjust and adapt to the "supplyside structural reform" under the "new normal", realizing that "China's sports industry will reach 5 trillion by 2025; and China's GDP growth will be much higher than the current contribution of the sports industry. It will truly become the new driving force for economic development and the new kinetic energy of consumption upgrading.

\section{THE INTERNAL CONSISTENCY OF THE NEW NORMAL AND SUPPLY-SIDE STRUCTURAL REFORM}

In May 2014, General Secretary Xi Jinping pointed out during his inspection in Henan: China's development is still in an important period of strategic opportunities. We must enhance our confidence, proceed from the current stage of China's economic development, adapt to the new normal, and maintain a strategically normal attitude [3]. The term "new normal" was first proposed by Mr. Mohamed El Erian (President of the US Pacific Fund Management Corporation), and is a pessimistic expression of the long-term stagnation of economic development in Western countries. The new Chinese normality proposed by General Secretary Xi Jinping is the clarion of reform and development. It clearly points out the direction of China's economic transformation. It also points out the dynamic structure of transformation [4], which mainly refers to the transformation from the rapid development of the past to a brand new relatively stable normality. It is a process of optimization, adjustment, transformation, and upgrading in parallel [5]. According to the report of National Bureau of Statistics Data Center, on the one hand, China's GDP growth rate has bid farewell to the average growth of about $10 \%$ in the past 30 years, from $8.7 \%$ in 2000 to $14.2 \%$ in 2007 , and then to $6.7 \%$ in 2016 . On the other hand, the total GDP is 4.22 times that of 2000 The goal of the gross domestic product proposed by the party's 16th national congress quadrupling by 2020 compared with that of 2000 has been achieved four years ahead. Per capita GDP has entered the ranks of middle-class countries. The large surplus of labor has disappeared, and 
economic development has entered the new normal of "from high-speed growth to medium-high-speed growth, continuous optimization and upgrading of economic structure, from factor-driven, investment-driven to innovation-driven" as stated by General Secretary Xi Jinping. The new normal means that China already adopts supplydetermined economy under normal conditions: the output of the economy is determined by its supply or production capacity, not by the investment, consumption and exports. The goal is to develop a knowledge-intensive economy to improve the technical level or total factor productivity of the economy and society [6], vigorously develop the tertiary industry, and increase the proportion of the tertiary industry in the national economy. Based on this, General Secretary Xi Jinping proposed the concept of "supply-side structural reform" at the eleventh meeting of the Central Financial and Economic Leading Group held in November 2015. It is to use reforms to promote structural adjustment and reduce inefficiency and low-end supply. And it will expand effective and medium-high-end supply, and enhance the adaptability and flexibility of the supply structure to the demand structure [7]. This is basic analysis and accurate judgment of the current economic and social situation, as well as a major reform measure under the new normal of economic development, and a key measure to improve the quality of China's economic growth. Therefore, promoting the supply-side structural reform under the new normal is a key measure to improve the quality of China's economic growth. Under the current situation, the supply-side structural reform is consistent with the basic characteristics, connotation and internal logic of the new normal [8]. Of course, emphasizing the reform of the economic growth from the supply side does not mean that the demand side is not important [9]. As Prime Minister Li Keqiang said, when both the supply side and the demand side are simultaneously exerted can the economy continue to grow?

\section{PROSPECTS FOR THE NEW NORMAL OF THE SPORTS INDUSTRY}

The sports industry refers to the total of various industries that produce sports materials and spiritual products and provide related services. According to the statistics of the US Prangett Company, the global sports industry added value of 1.5 trillion US dollars in 2014, which is a veritable emerging industry, green industry and sunrise industry? It has the characteristics of large development potential, wide radiation range, high correlation, long industrial chain, strong driving action, low resource consumption and high added value. In the 10 years from 2004 to 2013, the total size of China's sports industry has increased nearly three times, and the average annual growth rate has reached $16.18 \%$, far exceeding the growth rate of national GDP in the same period. And it has become a new engine to lead economic growth [10]. The sports industry is the sixth pillar industry of the United States. The total output value is twice that of the automobile industry, accounting for more than 3\% of GDP, and the contribution rate to employment is $11 \%$, even exceeding that of the industries of agriculture and railways. The proportion of the sports industry in GDP is about $0.7 \%$, which is a huge gap with the developed countries such as the
United States and Europe (The United States only calculates the core sports events, sports competitions and sports communications when estimating the sports industry, and China calculates various peripheral incomes such as shoes and clothing). It also left us a huge room for development. After China's economy entering a new normal, the sports industry has been paid much attention in "promoting consumption, maintaining growth, adjusting structure, and benefiting people's livelihood." In recent years, the state has issued a number of important documents such as "Several Opinions on Accelerating the Development of Sports Industry to Promote Sports Consumption", "2030 Outline for Healthy China", and "National Fitness Program (20162020)". It has set a goal of achieving a total output value of 5 trillion RMB by 2025 , and the industrial structure has been gradually optimized, promoting the integrated development continuously. The successful experience of developed countries and the practice after the implementation of China's new sports industry policy proves that the sports industry is a sunrise industry with broad development prospects, and the development of sports industry has ushered in a new era of transformation and upgrading [11]. This puts new demands on the development of the sports industry, provides new opportunities for the development of the sports industry, and injects new impetus into the development of the sports industry. Taking national fitness as the leader, taking sports events and sports tourism as the core, the mode of development has been changed from government subject to social subject; the industrial structure has been transformed from manufacture-oriented to serviceoriented; the consumption content has been transformed from material product consumption to service consumption; and the business form has been transformed from single to multi-industry integration. The sports industry has entered into new normal of high-speed development.

\section{RESEARCH ON THE DEVELOPMENT PATH OF SUPPLY- SIDE STRUCTURAL REFORM OF SPORTS INDUSTRY}

With the improvement of people's living standards and the surge in demand for sports consumption, the contradiction between the oversupply of the sports industry and the lack of effective supply has become increasingly prominent. It has placed urgent demands on the supply-side structural reform of the sports industry. This is the logical starting point of the structural reform of the sports industry [13]. As we all know, institutional reform, structural optimization, and factor upgrading (corresponding reform, transformation, and innovation) are the "three engines" for the supply side. Only by fully recognizing that people's sharing of sports development results is the starting point for developing sports industry and promoting sports consumption. According to the supply-side structural reform of the sports industry, it can meet the diversified sports needs of the people, truly realizing the innovation, coordination, green, open and shared development of the sports industry. 


\section{A. Deepening System Supply and Innovation, Further} Improving and Implementing the Policy System

Economic scholar Jia Kang believes that it is necessary to improve the supply environment, optimize the supply-side mechanism, and stimulate the vitality of individuals and enterprises by improving the system supply. The specific performance is to further promote the reform of the administrative examination and approval system of "streamlining administration, delegating power to the lower levels, strengthening regulation and optimizing the services". Since the State Council issued "Several Opinions on Accelerating the Development of Sports Industry to Promote Sports Consumption", the national ministries and commissions have responded positively and issued nearly 30 supporting documents. The provinces (autonomous regions and municipalities) have also taken the initiative to implement the implementation opinions of the sports industry. It has initially formed a policy system to support the development of the sports industry. It is estimated that the total scale of the sports industry in the provinces in 2025 will be nearly 7 trillion yuan. However, there is a gap between ideals and reality. Many policies lack operability, and implementation is difficult. There are problems of "focusing policy formulation and lighting policy implementation. The "top design" has not been "precisely implemented". If we still follow the previous inertial thinking and only expand the sports industry from the scale, rather than break through the system and mechanism, we will not be able to enhance the competitiveness of the sports industry. Thus, we will not be able to achieve sustainable and healthy development of the sports industry [14]. Specifically, it is not possible to ignore the organization of competitions because of the cancel of the approval of commercial and mass events. We must delegate power and strengthen regulation, clarify the role of the government, the market, and society, and vigorously support private capital entering the sports industry. This has stimulated their vitality for the "relaxation" of enterprises. It has provided services in transportation, security, and ambulance, promoting the development of the sports industry and national fitness.

\section{B. Effectively Promoting Sports Consumption and Building Reasonable Sports Industrial Structure}

The cornerstone and foundation of sports consumption are mainly driven by the national fitness. It is empty talk to stimulate sports consumption to drive the development of the sports industry without enough people [15]. In general, the concept of sports consumption of the masses in China is still not strong. Taking national fitness as a national policy, China's huge population base provides a huge space and possibility for promoting sports consumption. By 2020, the number of people who take part in physical exercise once a week or more will reach 700 million, and the number who often take part in physical exercise will reach 435 million, and the total scale of sports consumption will reach 1.5 trillion yuan. There are three main categories of sports consumption. One is the physical consumption for the purchase of sporting goods and equipment. The second is for viewing various sports competitions, events, and exhibitions. The third is for participatory consumption such as various sports activities, fitness training and health care. At present, China's sports consumption is dominated by physical consumption. The other two categories of consumption are low, which has enormous potential for development. According to the experience of developed countries, the proportion of sports service industry in the total sports industry is a core indicator to determine whether a country's sports industry structure is reasonable. At present, the average proportion of the sports service industry in the 16 developed countries such as the United States, Britain and Germany exceeds $60 \%$, while the proportion of China's sports service industry is less than $30 \%$. The proportion is too small, and the role of leading consumption has not been fully exerted. At present, China's economy has entered the era of "service", and the service industry has become a new driving force for China's economic growth under the new normal. Therefore, it is necessary to grasp the opportunity of vigorously developing the tertiary industry in the current state. It should increase the effective supply of the sports service industry, innovate sports service products while accelerating the construction of sports facilities, better stimulate the enthusiasm of the masses to participate in sports activities, and promote the formation of a healthy investment concept. Then, we can establish a vibrant sports consumer market [16], build a reasonable sports industry structure and promote its healthy development.

\section{Handling the Contradiction Between Ineffective Oversupply and Inadequate Effective Supply}

General Secretary Xi Jinping pointed out, at present and in the future, the factors restricting China's economic development are on both sides of supply and demand. However, the main aspects of contradiction are on the supply side. The ineffective and low-end supply is too much. Effective supply and low-end supply are insufficient. The diversified, personalized, high-end demand is difficult to meet. This phenomenon also exists in the sports industry. On the one hand, with the development of social economy and the change of life concept, people's demand for sports is increasing day by day. From 51 games in 2014 to 134 games in 2015 and 328 games in 2016, the number of domestic marathon events has been increasing. No one cares in the past, however, the participants needs to draw lots. It reflects that the concept of mass has changed from the appreciation to the combination of appreciation and development. And the demand is strong. Compared with the current growing demand for sports industry, on the other hand, effective supply and mid-to-high end supply are insufficient. For example, in 2015, China's per capita sports area is about $1.6 \mathrm{~m} 2$, which is less than one tenth of people at the same period in the United States. The phenomenon of uneven urban and rural areas and regional imbalance is obvious. The aunts want to dance in square, and they will compete with the students or the car owner to get the stadium or the car parking. At the same time, the innovation ability of clothing and equipment products is not strong, the key core technologies are lacking, and the homogenization is serious. It is difficult to compete effectively with similar foreign products, and it is difficult to meet the needs of the masses after upgrading. Taking Anta's revenue of 2016 sports shoes 
sales of 40 million pairs for the first time to break through 10 billion, it outnumbered Nike in number. However, whether it is in function, design, or revenue (according to Nike's turnover of 27.23 billion US dollars, 2016), the two brands are not in the same order. Nike's advantages in high-end products are still obvious. It can be seen that the development of the middle-to-high-end market should fully use market mechanisms [17] and economic means. The supply will meet the demand. The "industry 4.0 " has become the key to the future development of sports enterprises in China.

\section{Guiding by "Sports+" and "Internet+", Promoting the Integration, Innovation and Development}

"Sports+" and "Internet+" are the key to improving the potential economic growth rate of the sports industry and transforming potential into vitality [18]. Among 42 industrial fields in the United States, more than $47 \%$ of the departments are directly related to the sports industry, and the external correlation coefficient ranks sixth. It can be seen that the sports industry has formed a significant crossover with the external industry in the United States [19]. In today's era, sports are not isolated. They need to be deeply integrated with education, medical care, tourism, leisure, and old-age care to meet the health needs of different groups of people through higher quality products. Taking "sports + tourism" as an example, sports is an important resource for the development of tourism industry. Tourism is an important driving force for promoting the sports industry. The combination of characteristic events and specific tourism resources often produces " $1+1>2$ " effects. According to the latest data from the World Tourism Organization, the current average growth rate of the global tourism industry is only $2 \%-3 \%$. However, sports tourism is the segment with the fastest growth rate of $14 \%$. While enjoying the beauty, sports elements are increasingly integrated into the tourism industry. Skiing, surfing, diving and other projects let the participants enjoy it. Sports can create more added value for tourism.

The integration of "Internet + sports" is like ploughing to agriculture. For the sports industry, the Internet is an indispensable tool for its transformation, which can help improve the digitization and informatization of its industry, and also help the efficiency and demand of its supply sports products. For example, the Internet platform continuously outputs content through the introduction and creation of high-level events, attracts and aggregates users to carry out offline activities, and then guides users to purchase various intelligent sports equipment through various interests, and finally obtains a large number of sports habits, hobbies, and various big data such as behaviors and health status, software analysis and integration, providing users with various valueadded services from sports and fitness to health care [20], promoting the "Internet + sports" into the fast track of development.

\section{CONCLUSION}

Under the situation that China's economy continues to show a slowdown in growth, supply-side structural reform is both a challenge and an opportunity for the sports industry. It must fully expand the effective supply and effective demand for sports service products and strive to achieve dialectical unity of the two [21]. With the continuous deepening of supply-side structural reform, the development of technological revolution and industrial transformation, and the gradual implementation of the "healthy China" strategy, China's sports industry will expand from pursuing scale to improving quality and competitiveness, becoming the next expectation growing industry. It has realized the new vision of "strong spots will improve China" proposed by General Secretary Xi Jinping during his recent visit to the Beijing Winter Olympics.

\section{REFERENCES}

[1] Xi Jinping. Improving the supply-side structure as the main direction [EB/OL]. [2017-1-22]. http://news.xinhuanet.com/politics/201701/22/c_129457936.htm.

[2] General Administration of Sports of the People's Republic of China The 13th Five-Year Plan for the Development of Sports Industry [Z]. 2016-06-27.

[3] Zhang Duoshe. Xi Jinping's investigation in Henan province [EB/OL] [2014-5-10]. 05/10/c 126484765.htm.

[4] Liu Hailing, He Mei. Looking at the supply-side reform from the "new normal" of China's economic development [J]. Finance and Accounting Research, 2016, 1:65-69.

[5] Li Houqiang, Deng Ziqiang. Comprehensively and accurately grasping the connotation and characteristics of the new normal [N] Entrepreneur Daily, 2015-1-20 (1).

[6] Gong Gang. On the supply-side reform under the new normal state [J]. Journal of Nankai University (Philosophy and Social Sciences Edition), 2016, 2: 13-20.

[7] Li Jinxiang. Demand analysis and action strategy of supply-side reform for quality and safety of livestock and poultry products in China [J]. Quality and Safety of Agricultural Products, 2017, 1:3-8.

[8] Zhang Weijie, Li Shaolin. China's supply-side structural reform under the new economic normal: theory, reality and policy [J]. Contemporary Economic Management, 2016, 38(4): 40-45.

[9] Huang Kainan. Co-evolution of supply side and demand side: based on the perspective of evolutionary growth $[\mathrm{J}]$. Southern Economy, 2015, 12: 1-9.

[10] Liu Liang, Fu Zhihua, Li Guihua. The New Space and Dynamic Cultivation of China's sports industry development from the perspective of supply-side reform[J]. Journal of Capital College of Physical Education, 2017, 29(1):8-12.

[11] Zhong Ze, Lin Fengli. Current development opportunities and challenges of China's sports industry [J]. Economic Aspects, 2016, 9: 29-32.

[12] Zhang Yongtao. The new normal of the development of China's sports industry: characteristics, challenges and transformation[J]. Sports and Science, 2015, 36(5):22-56.

[13] Shen Keyin, Lv Wangang. Supply-side structural reform of sports industry: theoretical logic, development reality and advancing ideas[J]. Journal of Wuhan Institute of Physical Education, 2016, 50(11): 30-41.

[14] Duan Jinjun, Zhang Minyi. Research on the innovation mechanism of sports industry development in the process of urbanization $[\mathrm{J}]$. Journal of Chengdu Sport University, 2015, 41(4): 7-56.

[15] Yi Jiandong. The status quo, opportunities and challenges of China's sports industry [J]. Journal of Wuhan Institute of Physical Education, 2016, 50(7):5-11 
[16] Several opinions of the State Council on accelerating the development of sports industry to promote sports consumption [Z]. 2014-10-20.

[17] Xu Kangning. Several theoretical issues and policy choices in supplyside reform [J]. Modern Economic Discussion, 2016, 6:5-9.

[18] Qi Ji. Research on the elements and action logic of supply-side structural reform in cultural industry [J]. Dong Yue Theory, 2016, 37(10): 15-21.

[19] Xu Zhengyong. Structural features of american sports industry and its enlightenment [J]. Sports Culture Guide, 2015,9:153-157.

[20] Xie Jingliang, Sun Jinhai, Cao Li. Opportunities, challenges and countermeasures for the development of China's sports industry in the age of big data[J]. Journal of Shanghai Physical Education Institute, 2015, 39(4): 59-63.

[21] Tang Xiuhua, Wang Haifei. Supply-side structural reform and optimization under the new normal state[J]. Statistics and Decision, 2017, 470(2): 64-67. 